
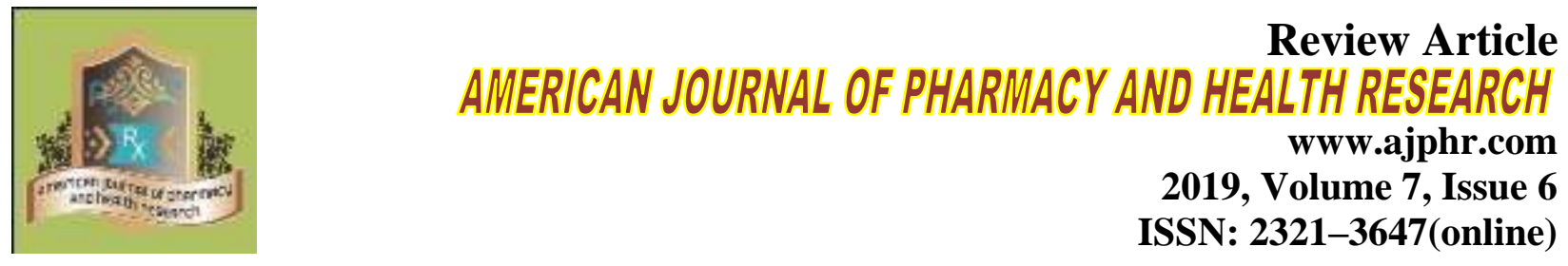

\title{
A Review On Proton Transfer Reaction Mass Spectroscopy
}

\author{
Bhavyasri K*, Surekha.T, R. Swethasri \\ 1.RBVRR Women's College of Pharmacy, Barkatpura, Hyderabad
}

\begin{abstract}
Proton transfer reaction mass spectrometry (PTR-MS) allows for real time, online determination of absolute concentrations of volatile organic compounds (VOCs) with a high sensitivity and low detection limits (in the parts per trillion ranges). The technique utilizes $\mathrm{H} 3 \mathrm{O}+$ ions for proton transfer reactions with many common VOCs while having little to no reaction with any constituents commonly present in it are detected by PTR- TOF .It combines the desirable attributes of high sensitivity and short integration times with good precision and accuracy . Medical applications by means of breath analysis allow the monitoring of metabolic processes in the human body, and examples of food research include investigations of volatile organic compound (VOC) emissions from fruit, coffee and meat. Investigations of VOC emissions from decaying bio-matter and on-line monitoring of the diurnal variations of VOCs in ambient air are typical examples of Environmental applications.
\end{abstract}

Keywords: PTR-MS, Volatile organic compounds, PTR -TOF. 


\section{INTRODUCTION}

Proton transfer reaction mass spectrometry (PTR - MS) was first developed at the Institute of Ion Physics of Innsbruck University in the 1990s. Nowadays, PTR - MS is a well-developed and commercially available technique for the online monitoring of trace volatile organic compounds (VOC s) down to parts per trillion by volume (pptv) level. PTR - MS has some advantages such as rapid response, soft chemical ionization (CI), absolute quantification, and high sensitivity. In general, a standard PTR - MS instrument consists of external ion source, drift tube, and mass analysis detection system. Figure 1 illustrates the basic composition of the PTR - MS instrument constructed in our laboratory using a quadruple mass spectrometer as the detection system $^{1}$.Volatile organic compounds (VOCs) are a large group of compounds with atmospheric lifetimes from seconds to months ${ }^{2}$. Volatile organic compounds (VOCs) are emitted into the atmosphere from both natural and anthropogenic sources and have lifetimes ranging from minutes to months. This diverse group of compounds is of interest in the troposphere because of their role in ozone (O3) production, aerosol formation and controls on regional air quality ${ }^{5}$. Commercially available PTR-MS instruments have response time of about $100 \mathrm{~ms}$ and reach a detection limit in the single digit pptv region. Established fields of application are environmental research, food and flavor science, biological research, medicine etc ${ }^{6}$.

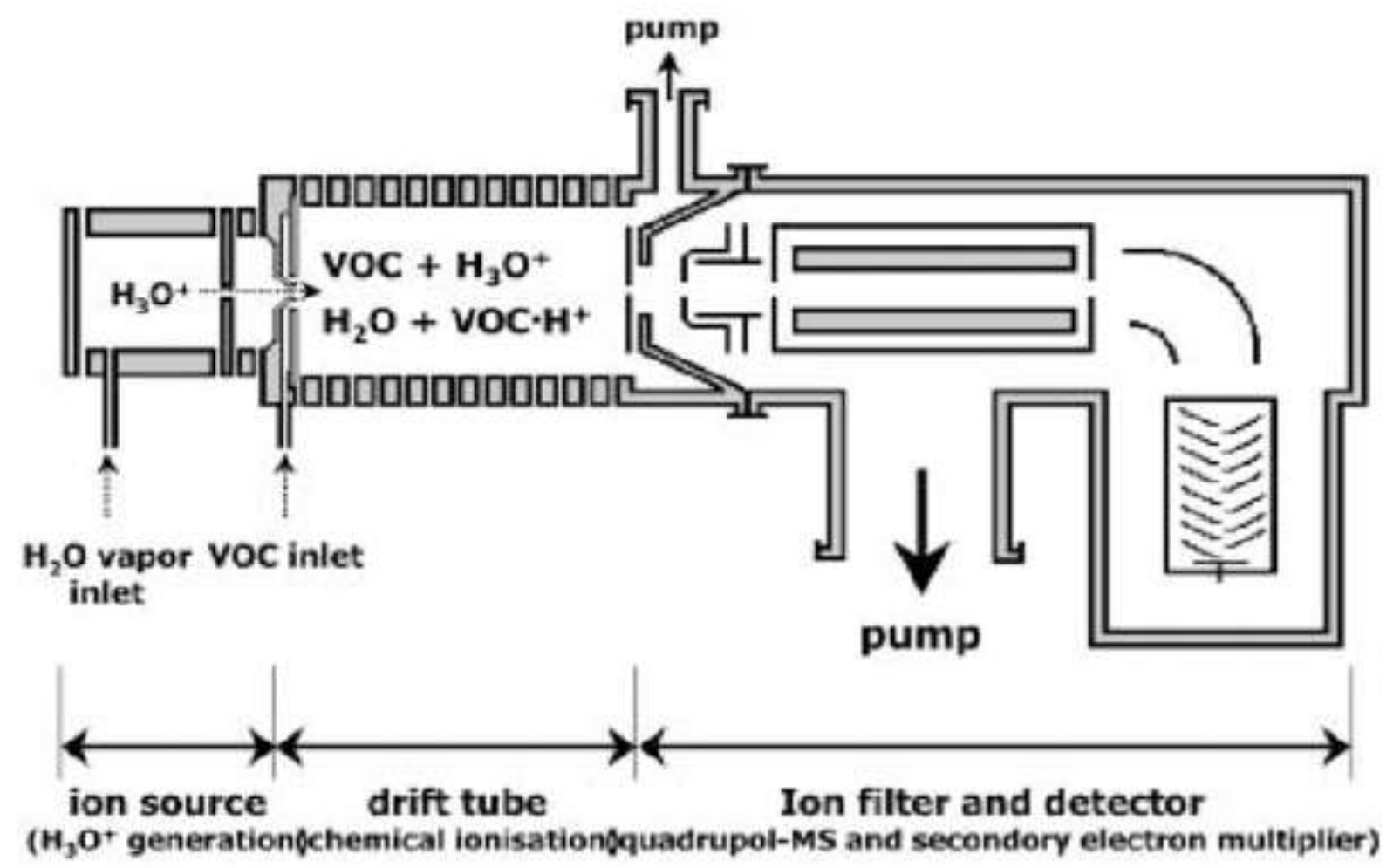

Figure: 1 PTR-MS Instrumentation 


\section{Ion Sources}

PTR - MS is the special CI mode through well - controlled proton transfer reaction, in which the neutral molecule $\mathrm{M}$ may be converted to a nearly unique protonated molecular ion $\mathrm{MH}+$. This ionization mode is completely different from traditional mass spectrometry (MS) where electron impact (EI) with energy of $70 \mathrm{EV}$ is often used to ionize chemicals like VOCs. Although the EI source has been widely used with the commercial MS instruments most coupled with a variety of chromatography techniques, these MS platforms have a major deficiency: in the course of ionization, the molecule will be dissociated to many fragment ions. This extensive fragmentation may result in complex mass spectra especially when a mixture is measured. If a chromatographic separation method is not used prior to MS, then the resulting mass spectra from EI may be so complicated that identification and quantification of the compounds can be very difficult. PTR MS instrument, the hollow cathode discharge is served as a typical ion source, although plane electrode direct current discharge and radioactive ionization sources ${ }^{1}$. In commercial PTR-MS instruments water vapor is ionized in a hollow cathode discharge. Due to the high purity of the primary ions a mass filter between the ion source and the reaction drift tube is not necessary and the $\mathrm{H} 3 \mathrm{O}+$ ions can be injected directly. The absence of this mass filter in turn greatly reduces losses of primary ions and leads eventually to an outstandingly low detection limit of the whole instrument. In the reaction drift tube a vacuum pump is continuously drawing through air containing the VOCs one wants to analyze. At the end of the drift tube the protonated molecules are mass analyzed (Quadruple or Time-of-flight mass spectrometer) and detected ${ }^{6}$.

$\mathrm{e}+\mathrm{H} 2 \mathrm{O} \rightarrow \mathrm{H} 2++\mathrm{O}+2 \mathrm{e}$

$\mathrm{e}+\mathrm{H} 2 \mathrm{O} \rightarrow \mathrm{H}++\mathrm{OH}+2 \mathrm{e}$

$\mathrm{e}+\mathrm{H} 2 \mathrm{O} \rightarrow \mathrm{O}+\mathrm{H} 2+2 \mathrm{e}$

$\mathrm{e}+\mathrm{H} 2 \mathrm{O} \rightarrow \mathrm{H} 2 \mathrm{O}+2 \mathrm{e}$

The above ions are injected into a short source drift region and further react with $\mathrm{H} 2 \mathrm{O}$ ultimately leading to the formation of $\mathrm{H} 3 \mathrm{O}+$ via ion molecule reactions. Instead of $\mathrm{H} 3 \mathrm{O}+$, other primary reagent ions, such as $\mathrm{NH} 4+, \mathrm{NO}+$, and $\mathrm{O} 2+$.Because the ion chemistry for these ions is not only proton transfer reaction, the technique is sometimes called CI reaction ${ }^{1}$.

\section{Drift Tube}

The drift tube consists of a number of metal rings that are equally separated from each other by insulated rings. Between the adjacent metal rings, a series of resistors is connected. A high voltage power supplier produces a voltage gradient and establishes a homogeneous electric field along the axis of the ion reaction drift tube. The primary $\mathrm{H} 3 \mathrm{O}+$ ions are extracted into the ion 
reaction region and can react with analyte $M$ present in the sample air, which through the inlet is added to the upstream of the ion reaction drift tube. According to the values of proton affinity (PA) (see Table -1), the reagent ion $\mathrm{H} 3 \mathrm{O}+$ does not react with the main components in air like $\mathrm{N} 2, \mathrm{O} 2$ and $\mathrm{CO} 2$. In contrast, the reagent ion can undergo proton transfer reaction with $\mathrm{M}$ as long as the proton affinity of $\mathrm{M}$ exceeds that of $\mathrm{H} 2 \mathrm{O}^{16}$.

$\mathrm{M}+\mathrm{H} 3 \mathrm{O} \quad \mathrm{MH}++\mathrm{H} 2 \mathrm{O}$

Thus, the ambient air can be directly introduced to achieve an online measurement in the PTR MS operation. Due to the presence of electric field, in the reaction region, the ion energy is closely related to the reduced field $\mathrm{E} / \mathrm{N}$, where $\mathrm{E}$ is the electric field and $\mathrm{N}$ is the number density of gas in the drift tube. In a typical PTR - MS measurement, E/N is required to set to an appropriate value normally in the range of $120 \sim 160 \mathrm{Td}(1 \mathrm{Td}=10-17 \mathrm{Vcm} 2 /$ molecule $)$, which may restrain the formation of the water cluster ions $\mathrm{H} 3 \mathrm{O}+(\mathrm{H} 2 \mathrm{O}) \mathrm{n}(\mathrm{n}=1-3)$ to avoid the ligands switch reaction with analyte6.

$\mathrm{H} 3 \mathrm{O}+(\mathrm{H} 2 \mathrm{O}) \mathrm{n}+\mathrm{M} \quad \mathrm{H} 3 \mathrm{O}++(\mathrm{H} 2 \mathrm{O}) \mathrm{n}-1 \mathrm{M}+\mathrm{H} 2 \mathrm{O}$

However, a higher reduced - field E/N can cause the collision - induced dissociation (CID) of the protonated products, thereby complicating the identification of detected analytes ${ }^{1}$.

Table 1: Proton Affinities of Some Compouds ${ }^{5}$

\begin{tabular}{lll}
\hline Compound & Molecular compounds & Proton affinities \\
\hline Helium & $\mathrm{He}$ & 177.8 \\
Neon & $\mathrm{Ne}$ & 198.8 \\
Argon & $\mathrm{Ar}$ & 369.2 \\
Oxygen & $\mathrm{O}_{2}$ & 421 \\
Water & $\mathrm{H}_{2} \mathrm{O}$ & 691 \\
Acetonitrile & $\mathrm{CH}_{3} \mathrm{CN}$ & 779.2 \\
Acetone & $\mathrm{CH}_{3} \mathrm{COCH}$ & 812 \\
Benzene & $\mathrm{C}_{6} \mathrm{H}_{6}$ & 750.4 \\
Ethanol & $\mathrm{C}_{2} \mathrm{H}_{5} \mathrm{OH}$ & 776.4 \\
\hline
\end{tabular}

\section{Mass Analyzer}

A mass analyzer is the component of the mass spectrometer that takes ionized masses and separates them based on charge to mass ratios and outputs them to the detector where they are detected and later converted to a digital output. The 2 types of mass analyzers used are Quadruple mass analyzer and Time of flight mass analyzers ${ }^{7}$.

\section{Quadrupole Mass Analyzer}

The DC bias will cause all the charged molecules to accelerate and move away from the center line, the rate being proportional to their charge to mass ratio. If their course goes off too far they 
will hit the metal rods or the sides of the container and be absorbed. So the DC bias acts like the magnetic field $\mathrm{B}$ of the mass spec and can be tuned to specific charge to mass ratios hitting the detector. The two sinusoidal electric fields at 90 orientations and 90 degrees phase shift will cause an electric field which oscillates as a circle over time ${ }^{17}$. So as the charged particles fly down toward the detector, they will be traveling in a spiral, the diameter of the spiral being determined by the charge to mass ratio of the molecule and the frequency and strength of the electric field. The combination of the DC bias and the circularly rotating electric field will be the charge particles will travel in a spiral which is curved. So by timing the peak of the curved spiral to coincide with the position of the detector at the end of the quadruple, a great deal of selectivity to molecules charge to mass ratio can be obtained ${ }^{6}$.

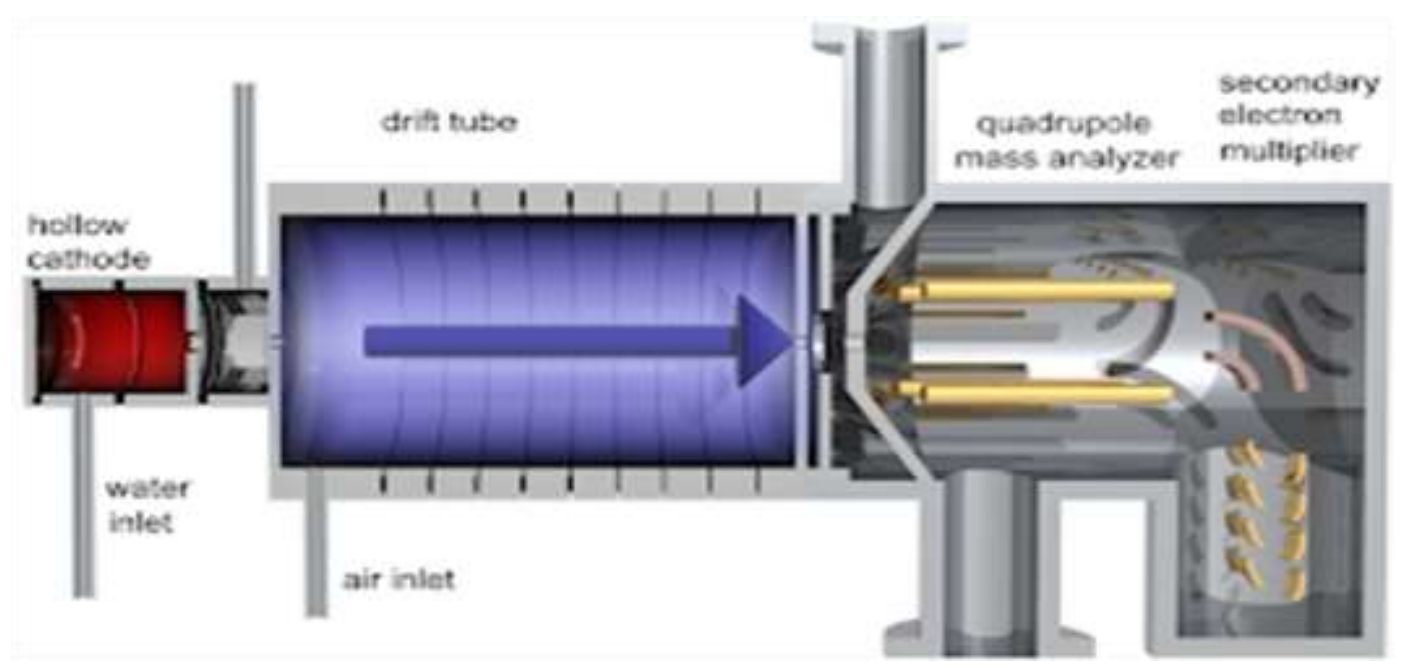

Figure: 2 PTR- Quadrupule Mass Analyzer

\section{Time of Flight Mass Analyzer}

TOF Analyzers separate ions by time without the use of an electric or magnetic field. TOF is similar to chromatography, except there is no stationary or mobile phase; instead the separation is based on the kinetic energy and velocity of the ions. It uses fixed voltages and does not require a magnetic field. Higher mass will reach the detector first. Ions produced acquire different velocities depending on the masses ${ }^{11}$. 


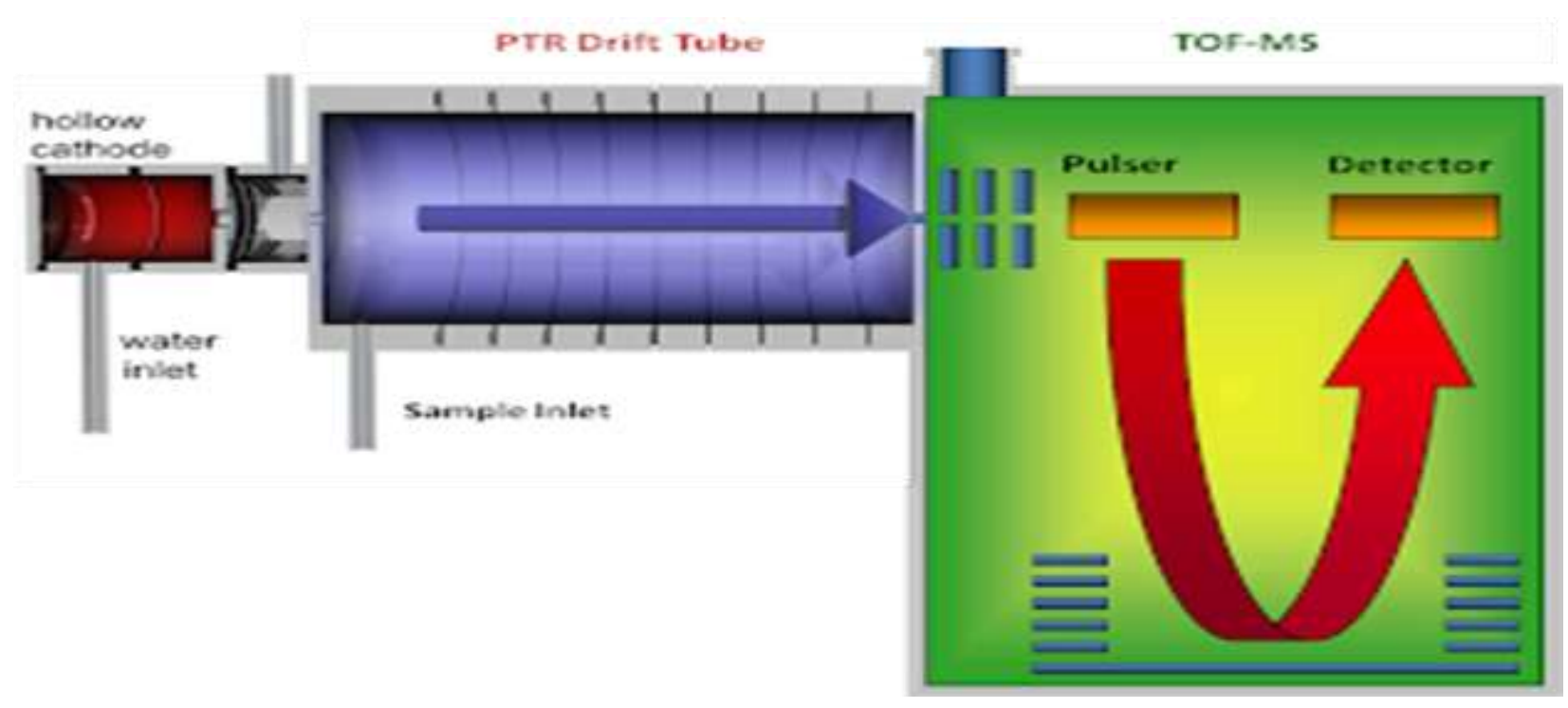

Figure: 3 PTR- TOF mass analyzer

\section{APPLICATIONS}

- Field of atmospheric monitoring.

- Some of the volatile compounds those are toxic to human.

- ROOT ANALYSIS: Diuraphis noxia with Arabidopsis roots resulted in the rapid release of 1, 8-cineole, a monoterpene.

- Local emissions from specific plants like methanol, acetaldehyde, ethanol, acetone, acetic acid, isoprene, toluene, josmonic acid etc which are emitted from Mediterranean helm oak( Quercus ilex) ${ }^{15}$.

- Tropical forests - (reactive trace gases) isoprene and degradation products like methyl vinyl ketone, methacrolien and isoprene hydro peroxides.

- Breath gas analysis: a sweet, fruity breath aroma originates from high levels of acetone in patients with diabetes.

- Breathe markers that can be used to detect a specific histological type of lung cancer.

- Monitoring the gas of fermentations in the biopharmaceutical industry allows microbial activity.

- Breath marker for smoking is acetonitrile.

- Analysis of "sticky" volatile compounds.

- Detecting three VOCs that are common in human urine: methanol, acetaldehyde, and acetone $^{10}$. 
- To assess the freshness of meat in air packing conditions: (aerobic bacteria - Entero bacteria, Pseudomonas produce protonated diethyl sulphide, thioacetic acid methyl ester) $)^{1}$.

- Quantitative long-term measurements of VOC concentrations of methanol and acetone annual cycle at a boreal forest $\operatorname{site}^{14}$.

- Analysis of volatile compounds in olive fruits ${ }^{4}$.

- The chemical compounds of interest released from T. pseudomonana were influenced by the growth phase of the diatoms can be analyzed ${ }^{7}$.

- Long-term study of VOCs measured with PTR-MS at a rural site in New Hampshire with urban influences ${ }^{5}$.

- Rapid online tool for biogas VOCs monitoring in support of the development of Solid Oxide Fuel Cells 9 .

\section{CONCLUSION}

PTR-MS is a high sensitivity, rapid and non-invasive "sensor" which can be used for the monitoring of volatile compounds. It has been successfully applied to a variety of fields including environmental science, food science and technology, plant physiology and medical science. In some cases PTR-MS has been used for the identification and quantification of relevant compounds but it can also be used as rapid highly specific MS.

\section{REFERENCES}

1. Yujie Wang, Chengyin Shen, Joaquin Li, Haihe Jiang, Yunnan Chu, Mass Spectrometry Handbook, First Edition, John Wiley \& Sons, 2012 ,605-630.

2. Ruuskanen TM, Taipale R, Rinne J, Kajos MK, Hakola H, Kulmala M. Quantitative long-term measurements of VOC concentrations by PTR-MS: annual cycle at a boreal forest site. Atmospheric Chemistry and Physics Discussions. 2009, 9(1):81-134.

3. Masi E, Romani A, Pandolfi C, Heimler D, Mancuso S. PTR-TOF-MS analysis of volatile compounds in olive fruits. Journal of the Science of Food and Agriculture. 2015, (7):1428-34.

4. Jordan C, Fitz E, Hagan T, Sive B, Frinak E, Haase K, Cottrell L, Buckley S, Talbot R. Long-term study of VOCs measured with PTR-MS at a rural site in New Hampshire with urban influences. Atmospheric Chemistry and Physics. 2009, 9(14):4677-97. 
5. Munson MS, Field FH. Chemical ionization mass spectrometry. I. General introduction. Journal of the American Chemical Society. 1966, (12):2621-30.

6. Ferguson EE, Fehsenfeld FC, Schmeltekopf AL. Flowing afterglow measurements of ion-neutral reactions. In Advances in atomic and molecular physics 1969 (Vol. 5, 1-56).

7. Kameyama S, Tanimoto H, Inomata S, Suzuki K, Komatsu DD, Hirota A, Konno U, Tsunogai U. Application of PTR-MS to an incubation experiment of the marine diatom Thalassiosira pseudonana. Geochemical Journal. 2011; 45(5):35563.

8. Inomata S, Tanimoto H, Aoki N, Hirokawa J, Sadanaga Y. A novel discharge source of hydronium ions for proton transfer reaction ionization: design, characterization, and performance. Rapid Communications in Mass Spectrometry: An International Journal Devoted to the Rapid Dissemination of Up to the Minute Research in Mass Spectrometry. 2006, (6):1025-9.

9. Dupeyrat G, Rowe BR, Fahey DW, Albritton DL. Diagnostic studies of venturi inlets for flow reactors. International Journal of Mass Spectrometry and Ion Physics. 1982, 44(1-2):1-8.

10. De Gouw J, Warneke C. Measurements of volatile organic compounds in the earth's atmosphere using proton-transfer-reaction mass spectrometry. Mass spectrometry reviews. 2007, (2):223-57.

11. . Blake RS, Whyte C, Hughes CO, Ellis AM, Monks PS. Demonstration of proton-transfer reaction time-of-flight mass spectrometry for real-time analysis of trace volatile organic compounds. Analytical Chemistry. 2004, 76(13):3841-5.

12. Ennis CJ, Reynolds JC, Keely BJ, Carpenter LJ. A hollow cathode proton transfer reaction time of flight mass spectrometer. International Journal of Mass Spectrometry. 2005, 247(1-3):72-80.

13. Bamberger I, Hörtnagl L, Ruuskanen TM, Schnitzhofer R, Muller M, Graus M, Karl T, Wohlfahrt Gand Hansel A. Deposition fluxes of terpenes over grassland. Journal of Geophysical Research: Atmospheres. 2011, 116-120.

14. Ammann C, Spirig C, Neftel A, Steinbacher M, Komenda M, Schaub A. Application of PTR-MS for measurements of biogenic VOC in a deciduous forest. International Journal of Mass Spectrometry. 2004, 239(2-3):87-101. 
15. Bonsang B, Polle C, Lambert G. Evidence for marine production of isoprene. Geophysical Research Letters. 1992, 19(11):1129-32.

16. Keck L, Oeh U, Hoeschen C. Corrected equation for the concentrations in the drift tube of a proton transfer reaction-mass spectrometer (PTR-MS). International Journal of Mass Spectrometry. 2007, 264(1):92-95.

17. Prazeller P, Palmer PT, Boscaini E, Jobson T, Alexander M. Proton transfer reaction ion trap mass spectrometer. Rapid communications in mass spectrometry. 2003 17(14):1593-1598.

AJPHR is

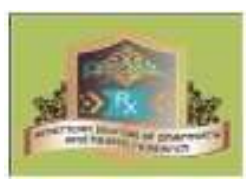

Peer-reviewed monthly

Rapid publication

Submit your next manuscript at editor@ajphr.com / editor.ajphr@gmail.com 